\title{
THE
}

\section{Highly Efficient Quenching of Nanoparticles for the Detection of Electron-Deficient Nitroaromatics}

\author{
Patrick Marks \\ University of Rhode Island \\ Sage Cohen \\ University of Rhode Island \\ Mindy Levine \\ University of Rhode Island, m_levine@uri.edu
}

Follow this and additional works at: https://digitalcommons.uri.edu/chm_facpubs

\section{The University of Rhode Island Faculty have made this article openly available.}

Please let us know how Open Access to this research benefits you.

This is a pre-publication author manuscript of the final, published article.

Terms of Use

This article is made available under the terms and conditions applicable towards Open Access Policy Articles, as set forth in our Terms of Use.

\section{Citation/Publisher Attribution}

Marks, P., Cohen, S., \& Levine, M. (2013), Highly efficient quenching of nanoparticles for the detection of electron-deficient nitroaromatics. J. Polym. Sci. Part A: Polym. Chem., 51, 4150-4155. doi: 10.1002/ pola.26824

Available at: http://dx.doi.org/10.1002/pola.26824 
TITLE: Highly Efficient Quenching of Nanoparticles for the Detection of Electron-Deficient Nitroaromatics

AUTHORS: Patrick Marks, ${ }^{1}$ Sage Cohen, ${ }^{2}$ and Mindy Levine ${ }^{1}$

INSTITUTION ADDRESS: ${ }^{1}$ Department of Chemistry, University of Rhode Island, 51 Lower College Road, Kingston, RI 02881; 401-874-4243

${ }^{2}$ South Kingstown High School, South Kingstown, Rhode Island

Email: mlevine@chm.uri.edu

ABSTRACT: Reported herein is the highly efficient quenching of fluorescent organic nanoparticles by 2,4-dinitrotoluene (DNT) and 2,4,6-trinitrotoluene (TNT). These fluorescent nanoparticles are formed from the hydrophobic collapse of fluorescent polymer chains, and display quenching efficiencies that are in line with the highest reported literature values. Moreover, the fluorescent quenching occurs only for the fluorescent nanoparticles, and not for the precursor polymer solutions, which display marked insensitivity to the presence of nitroaromatics. This aggregation-dependent fluorescent quenching has numerous applications for the detection of small-molecule electron-deficient analytes.

KEYWORDS: Nanoparticles, fluorescence, conducting polymers

INTRODUCTION: Researchers have had remarkable success in developing detection methods for electron-deficient nitroaromatic explosives such as 2,4,6-trinitrotoluene (TNT), and for the non-explosive but structurally related 2,4-dinitrotoluene (DNT) (Chart 1). ${ }^{1-3}$ These detection methods have significant practical applications for national security, and have been used in airport screening systems ${ }^{4}$ and in the detection of land mines in Iraq and Afghanistan. ${ }^{5}$ Such methods include the use of amplified fluorescent quenching of conjugated poly(phenyleneethynylenes) (PPEs) ${ }^{6,7}$ and other fluorescent polymers, ${ }^{8}$ quenching of fluorescent 
silica nanoparticles, ${ }^{9}$ and quenching of metallic nanoparticles. ${ }^{10}$ Using such methodology, detection limits as low as $1 \mathrm{fg}$ (femtogram) have been obtained. ${ }^{11}$

Many of the previously-reported detection methods rely on the quenching of fluorescent polymers in the solid state, for example, in spin-cast thin films or in capillary tubes. The fluorescence quenching in such aggregated states is generally higher than quenching observed in solution, due to the ability of the fluorescent polymers to have inter-chain exciton migration in addition to intra-chain migration. ${ }^{12}$

Another way to ensure inter-chain communication between polymer chains is to confine them in non-covalently linked fluorescent nanoparticles, often referred to as "polymer dots." ${ }^{.13}$ Such particles can be fabricated in a number of ways, including: (a) the hydrophobic collapse of the polymer chain when introduced into an aqueous solvent, also called "re-precipitation,"14,15 and (b) synthesis in mini-emulsions stabilized by surfactants. ${ }^{16}$ Despite the ubiquity of such nanoparticles in biological detection schemes, ${ }^{17}$ they have been used only rarely for explosive detection. In one example, polythiophene nanoparticles were used for DNT detection, with a reported quenching constant of $2706 \mathrm{M}^{-1}{ }^{18}$ Oligo(tetraphenyl)silole nanoparticles have also been used, with a quenching constant of up to $5000 \mathrm{M}^{-1}$ in the presence of DNT. ${ }^{19}$ The quenching of other fluorescent nanoparticles by nitroaromatics has not been reported.

Reported herein is the use of fluorescent nanoparticles fabricated by re-precipitation methods from 2,1,3-benzooxadiazole-alt-polyfluorene (PFBO, compound 5) and 2,1,3-benzothiadiazolealt-polyfluorene (PFBT, compound 6) for the detection of DNT and TNT (Chart 2). Quenching constants up to $6.9 \times 10^{3} \mathrm{M}^{-1}$ were observed for PFBO nanoparticles exposed to DNT $(0.17 \mathrm{mM}$ DNT), and $1.2 \times 10^{4} \mathrm{M}^{-1}$ for PFBT nanoparticles in the presence of TNT $(0.14 \mathrm{mM}$ TNT). These 
quenching efficiencies clearly establish the general use of fluorescent nanoparticles in nitroaromatic-induced quenching schemes.

\section{EXPERIMENTAL:}

Materials and Methods: All chemicals were purchased from Sigma-Aldrich Chemical Company and used as received, unless otherwise noted. ${ }^{1} \mathrm{H}$ NMR spectra were obtained using a Bruker 300 MHz spectrometer. UV-Visible spectra were obtained using an Agilent 8453 spectrometer equipped with a photodiode array detector. Fluorescence spectra were obtained using a Shimadzu RF-5301PC spectrophotofluorimeter and integrated vs. wavenumber. Dynamic light scattering (DLS) data were acquired using a Malvern Zetasizer Instrument. Gel permeation chromatography (GPC) data were acquired using a Waters GPC liquid chromatography system with an internal refractive index detector and two Waters Styragel HR-5E columns. Retention times were calibrated against polystyrene standards (Polymer Laboratories; Amherst, MA) to produce number average molecular weight $\left(\mathrm{M}_{\mathrm{n}}\right)$ and weight average molecular weight $\left(\mathrm{M}_{\mathrm{w}}\right)$ values. Thin films were spun using a Laurell Technologies Spin Processor.

Polymer Synthesis: The synthesis of polymers PFBO and PFBT followed literature-reported procedures. $^{20,21}$ The synthetic schemes for each polymer are shown below (Scheme 1 and Scheme 2).

Gel Permeation Chromatography: The molecular weight and size distribution of the newly synthesized polymers were determined by gel permeation chromatography, and the results are shown below:

\section{PFBO 5:}

$\mathrm{M}_{\mathrm{n}}=6.1976 \times 10^{3} \mathrm{~g} / \mathrm{mol}$

$\mathrm{M}_{\mathrm{w}}=8.8652 \times 10^{3} \mathrm{~g} / \mathrm{mol}$ 
$\mathrm{PDI}=1.43$

\section{PFBT 6:}

$\mathrm{M}_{\mathrm{n}}=6.3503 \times 10^{3} \mathrm{~g} / \mathrm{mol}$

$\mathrm{M}_{\mathrm{w}}=1.7003 \times 10^{4} \mathrm{~g} / \mathrm{mol}$

$\mathrm{PDI}=2.68$

Nanoparticle fabrication: Nanoparticles were formed following literature-reported procedures. ${ }^{22}$ Briefly, $2 \mathrm{~mL}$ of a polymer solution $(0.01 \mathrm{~g} / \mathrm{L})$ dissolved in THF was quickly added to $8 \mathrm{~mL}$ of deionized water, while sonicating the water. After addition of the polymer solution, nitrogen was bubbled through the solution for one hour to remove the THF.

Fluorescence quenching experiments: In quenching experiments, two solutions were made: one containing dilute particles in water with acetonitrile (solution A), and one with dilute particles in water and DNT in acetonitrile (solution B).

The water-acetonitrile solutions were allowed to equilibrate for 1 hour prior to analysis. Absorbance spectra of all particle solutions were recorded, and the absorbance at the excitation wavelength was checked to be below 0.1 absorbance units.

$2.5 \mathrm{~mL}$ of the particle solution in water/acetonitrile (solution A) was added to the cuvette, and the fluorescence was recorded. Three $500 \mu \mathrm{L}$ aliquots of the DNT/particle solution (solution B) were added to the cuvette, and the fluorescence was re-recorded after each addition. The cuvette was then filled with $1.25 \mathrm{~mL}$ solution $\mathrm{A}$ and $1.25 \mathrm{~mL}$ solution $\mathrm{B}$. Three $500 \mu \mathrm{L}$ aliquots of B were added, and fluorescence recorded after each addition. Finally, the fluorescence of solution B by itself was recorded.

All PFBO solutions were excited at $400 \mathrm{~nm}$, and all PFBT solutions were excited at $420 \mathrm{~nm}$. 
The fluorescence emission spectra were integrated vs. wavenumber on the X-axis. Plotting the concentration of analyte (DNT or TNT) in molarity on the X-axis vs. $I_{0} / I$ (initial integrated emission in the absence of the analyte divided by the integrated emission in the presence of the analyte) on the Y-axis yielded Stern-Volmer plots. The data were fit to linear relationships to determine the Stern-Volmer quenching constants. The $\mathrm{R}^{2}$ values for all linear fits were above 0.93 .

Thin film quenching: Thin films were spun-cast on a square glass cover slip (dimensions: $1 \mathrm{~cm} \mathrm{x}$ $1 \mathrm{~cm}$ ), by adding $0.2 \mathrm{~mL}$ of an $0.1 \mathrm{mg} / \mathrm{mL}$ solution of THF to the slip, then spinning it at 1000 RPM for 20 seconds. Thin film quenching was assessed by adding $10 \mathrm{mg}$ of DNT (compound 2) was added to a cuvette, and covering the cuvette for 2 hours. After 2 hours, the polymer thin film was dropped in, the cuvette was covered, and fluorescence intensity was immediately recorded. The intensity was recorded at a single wavelength in 1 second intervals for 20 minutes. (Polymer 5: Excitation at $430 \mathrm{~nm}$; emission monitoring at $500 \mathrm{~nm}$; polymer 6: excitation at $450 \mathrm{~nm}$; emission monitoring at $533 \mathrm{~nm}$ ).

RESULTS AND DISCUSSION: The newly synthesized polymers were characterized by ${ }^{1} \mathrm{H}$ NMR, GPC, UV-Visible absorption spectroscopy, and fluorescence spectroscopy, and the results are summarized in Table 1. The fluorescent nanoparticles were characterized by absorption and fluorescence spectroscopy (Table 2), and the formation of the particles was confirmed by dynamic light scattering measurements (DLS).

Remarkably, the fluorescent nanoparticles demonstrated highly efficient quenching in the presence of DNT and TNT, whereas the fluorescent polymers (from which the particles were synthesized) displayed no fluorescence quenching. All of the quenching efficiencies were fitted to the Stern-Volmer equation and displayed excellent linear fits. A summary of the Stern-Volmer 
constants for each particle-analyte combination is shown in Table 3, and examples of the quenching are shown in Figure 1.

This quenching displayed the following key features:

(a) Low limits of detection. The concentration of analytes required to achieve full quenching are shown in Table $3(0.17 \mathrm{mM}$ and $0.14 \mathrm{mM}$ for DNT and TNT respectively). However, in all cases, noticeable quenching was observed at substantially lower analyte concentrations. The addition of as little as $29 \mu \mathrm{M}$ of TNT to the nanoparticle solutions resulted in quenching, as did the addition of $23 \mu \mathrm{M}$ of DNT. While these detection limits are substantially greater than those reported by Trogler ${ }^{23}$ and Swager $^{24}$ for analogous thin-film systems, the use of nanoparticles to achieve quenching in this case provides operational advantages.

(b) Requirement of aggregation. While polymer-derived nanoparticles demonstrated efficient quenching, the polymers dissolved in chloroform solution displayed little to no quenching under otherwise identical conditions. Moreover, polymer-derived thin films, like polymer-derived nanoparticles, were efficiently quenched by DNT, which confirms that non-covalent aggregation of the polymer chains is necessary for efficient energy transfer. These thin films were fabricated from polymers 5 and $\mathbf{6}$ (see experimental section and ESI for details), and their fluorescence emission was monitored in the presence of DNT vapor (Figure 2). After 20 minutes, the fluorescence emission of polymer 5 in the film decreased to $10 \%$ of its maximum value, and the emission of polymer 6 decreased to $48 \%$ of its initial value.

(c) Significant solvent dependence. The quenching of polymer 6-derived nanoparticles also displayed a substantial dependence on the percentage of acetonitrile in the solution, with higher amounts of acetonitrile leading to less efficient fluorescent quenching. An example of such 
dependence is shown in Figure 3. With 6.25\% acetonitrile in water, the quenching proceeded with $\mathrm{K}_{\mathrm{SV}}=804 \mathrm{M}^{-1}$, whereas a $50 \%$ water-acetonitrile mixture yielded a $\mathrm{K}_{\mathrm{SV}}$ of $27 \mathrm{M}^{-1}$.

To explain this solvent dependence, dynamic light scattering (DLS) measurements of the particles in mixed solvents were collected, and the results are shown in Figure 4. For polymer 5 nanoparticles, the addition of acetonitrile increased in the average particle diameter from $24 \mathrm{~nm}$ to $38 \mathrm{~nm}$, but further addition of acetonitrile led to no noticeable change in the particle size (particles in $3.1 \%$ and $50 \%$ acetonitrile displayed the same average diameter).

Polymer 6 nanoparticles, by contrast, showed a marked increase in average diameter with increasing amounts of acetonitrile. Switching from $0 \%$ to $3.1 \%$ to $50 \%$ acetonitrile caused the particle diameter to increase from $18 \mathrm{~nm}$ to $58 \mathrm{~nm}$ to $78 \mathrm{~nm}$. This solvent-induced swelling caused the individual polymer chains in the nanoparticles to separate, which limited inter-chain aggregation and thus the nitroaromatic-induced quenching efficiencies.

The increased susceptibility of polymer $\mathbf{6}$ compared to polymer $\mathbf{5}$ is likely a result of the long alkyl chains on polymer 5 protecting the particles from swelling and acetonitrile-induced collapse. The lower density of alkyl chains on polymer $\mathbf{6}$ increases the particle susceptibility.

(d) Fluorescence lifetime decrease. Preliminary lifetime data indicate that the fluorescence lifetime of the nanoparticles is significantly decreased in the presence of nitroaromatic quenchers (lifetime of polymer 5 nanoparticles decreased from 1.8 ns to 1.7 ns; polymer 6 nanoparticles decreased from $0.73 \mathrm{~ns}$ (major species) to $0.47 \mathrm{~ns}$ (major species). These decreases indicate that dynamic quenching is likely occurring in this system. ${ }^{25}$

The generality of this fluorescent quenching was assessed by measuring the response of the nanoparticles to nitrobenzene (compound 3) and cyclohexanone (compound 4) (Chart 1). No significant quenching was observed for either nitrobenzene or cyclohexanone, for either 
nanoparticles or polymers. This selectivity is in line with similar literature reports, ${ }^{26,27}$ which indicate improved selectivity for DNT and TNT over nitrobenzene and other small-molecule analytes.

Finally, the complete insensitivity of the polymers to the presence of such nitroaromatics was determined by exposing THF solutions of PFBO and PFBT polymers to DNT concentrations 100 times higher than those used for significant quenching of nanoparticles. Even at such high concentrations, NO detectable quenching of the polymer fluorescence was observed (Figure 5), which again indicates the significant necessity of nanoparticle formation for the detection of electron-deficient analytes.

CONCLUSION: In summary, highly efficient quenching of fluorescent nanoparticles has been demonstrated with both TNT and DNT as analytes. The high sensitivity (as determined by $\mathrm{K}_{\mathrm{sv}}$ values) and selectivity (no response to cyclohexanone or nitrobenzene), means that such quenching has potentially significant applications in turn-off detection schemes. Efforts towards developing such systems are currently in progress and results will be reported in due course.

ACKNOWLEDGEMENTS: S.C. thanks the American Chemical Society Project SEED for support of this work, and P.M. thanks the University of Rhode Island Foundation for support of this work.

\section{CITATIONS}

\footnotetext{
${ }^{1}$ Toal, S. J.; Trogler, W. C. J. Mater. Chem. 2006, 16, 2871-2883.

${ }^{2}$ Rose, A.; Zhu, Z.; Madigan, C. F.; Swager, T. M.; Bulovic, V. Nature 2005, 434, 876-879.

${ }^{3}$ Li, D.; Liu, J.; Kwok, R. T. K.; Liang, Z.; Tang, B. Z.; Yu, J. Chem. Commun. 2012, 48, 71677169.
} 
${ }^{4}$ Potyrailo, R. A.; Nagraj, N.; Surman, C.; Boudries, H.; Lai, H.; Slocik, J. M.; Kelley-

Loughnane, N.; Naik, R. R. Trends Anal. Chem. 2012, 40, 133-145.

${ }^{5}$ Fisher, M. E.; la Grone, M.; Sikes, J. Proc. SPIE Int. Soc. Opt. Engin. 2003, 5089, 991-1000

${ }^{6}$ Yang, J.-S.; Swager, T. M. J. Am. Chem. Soc. 1998, 120, 11864-11873.

${ }^{7}$ Yang, J.-S.; Swager, T. M. J. Am. Chem. Soc. 1998, 120, 5321-5322.

${ }^{8}$ Balan, B.; Vijayakumar, C.; Tsuji, M.; Saeki, A.; Seki, S. J. Phys. Chem. B 2012, 116, 1037110378.

${ }^{9}$ Geng, J.; Liu, P.; Liu, B.; Guan, G.; Zhang, Z.; Han, M.-Y. Chem. Eur. J. 2010, 16, 3720-3727.

${ }^{10}$ Tu, R.; Liu, B.; Wang, Z.; Gao, D.; Wang, F.; Fang, Q.; Zhang, Z. Anal. Chem. 2008, 80, $3458-3465$.

${ }^{11}$ Rose, A.; Lugmair, C. G.; Miao, Y.-J.; Kim, J.; Levitsky, I. A.; Williams, V. E.; Swager, T. M. Proc. SPIE Int. Soc. Opt. Eng. 2000, 4038, 512-518.

${ }^{12}$ Andrew, T. L.; Swager, T. M. J. Polym. Sci. B Polym. Phys. 2011, 49, 476-498.

13 Tuncel, D.; Demir, H. V. Nanoscale 2010, 2, 484-494.

${ }^{14}$ Tian, Z.; Yu, J.; Wu, C.; Szymanski, C.; McNeill, J. Nanoscale 2010, 2, 1999-2011.

${ }^{15}$ Mai, Y.; Eisenberg, A. Acc. Chem. Res. 2012, 45, 1657-1666.

${ }^{16}$ Joumaa, N.; Lansalot, M.; Theretz, A.; Elaissari, A.; Sukhanova, A.; Artemyev, M.; Nabiev, I.; Cohen, J. H. M. Langmuir 2006, 22, 1810-1816.

${ }^{17}$ Wu, C.; Schneider, T.; Zeigler, M.; Yu, J.; Schiro, P. G.; Burnham, D. R.; McNeill, J. D.; Chiu, D. T. J. Am. Chem. Soc. 2010, 132, 15410-15417.

${ }^{18}$ Satapathi, S.; Li, L.; Anandakathir, R.; Samuelson, L. A.; Kumar, J. J. Macromol. Sci. A Pure Appl. Chem. 2011, 48, 1049-1054.

${ }^{19}$ Toal, S. J.; Magde, D.; Trogler, W. C. Chem. Commun. 2005, 5465-5467. 
${ }^{20}$ Hu, J.; Zhang, D.; Jin, S.; Cheng, S. Z. D.; Harris, F. W. Chem. Mater. 2004, 16, 4912-4915.

${ }^{21}$ Bouffard, J.; Swager, T. M. Macromolecules 2008, 41, 5559-5562.

${ }^{22}$ Szymanski, C.; Wu, C.; Hooper, J.; Salazar, M. A.; Perdomo, A.; Dukes, A.; McNeill, J. J.

Phys. Chem. B 2005, 109, 8543-8546.

${ }^{23}$ Sohn, H.; Calhoun, R. M.; Sailor, M. J.; Trogler, W.C. Angew. Chem. Int. Ed. 2001, 40, 21042105.

${ }^{24}$ Rochat, S.; Swager, T. M. ACS Appl. Mater. Interfaces 2013, 5, 4488-4502.

${ }^{25}$ Bonancia, P.; Vaya, I.; Climent, M. J.; Gustavsson, T.; Markovitsi, D.; Jimenez, M. C.;

Miranda, M. A. J. Phys. Chem. A 2012, 116, 8807-8814.

${ }^{26}$ Content, S.; Trogler, W. C.; Sailor, M. J. Chem. Eur. J. 2000, 6, 2205-2213.

${ }^{27}$ Nagarkar, S. S.; Joarder, B.; Chaudhari, A. K.; Mukherjee, S.; Ghosh, S. K. Angew. Chem. Int. Ed. 2013, 52, 2881-2885. 


\section{FIGURE CAPTIONS}

Chart 1: Electron-deficient analytes under investigation

Chart 2: Structures of the fluorescent organic polymers

Scheme 1: Synthesis of PFBO 5:

Scheme 2: Synthesis of PFBT 6:

Table 1: Properties of the PFBO and PFBT polymers

Table 2: Properties of the PFBO and PFBT-derived nanoparticles

Table 3: Stern-Volmer constants obtained for each analyte-fluorophore combination (maximum analyte concentrations in parentheses)

Figure 1: Examples of fluorescence quenching of (a) PFBT (6) particles with DNT (b) PFBO (5) particles with DNT (c) PFBT (6) particles with TNT and (d) PFBO (5) particles with TNT. Stern-Volmer plots are included as insets for each example.

Figure 2: Quenching of fluorescent thin films in the presence of DNT vapor. Polymer 5 emission monitored at $500 \mathrm{~nm}$; polymer 6 emission at $533 \mathrm{~nm}$.

Figure 3: Dependence of $\mathrm{K}_{\mathrm{sv}}$ values on the acetonitrile/water ratio. Measurements were obtained for PFBT nanoparticles $\left(2.5 \times 10^{-4} \mathrm{mg} / \mathrm{mL}\right)$ in the presence of DNT.

Figure 4: DLS measurements of (a) polymer 5 nanoparticles and (b) polymer 6 nanoparticles in the presence of increasing amounts of acetonitrile.

Figure 5: Insensitivity of (a) PFBO and (b) PFBT polymers to $17.2 \mathrm{mM}$ concentrations of DNT. 
GRAPHICAL ABSTRACT

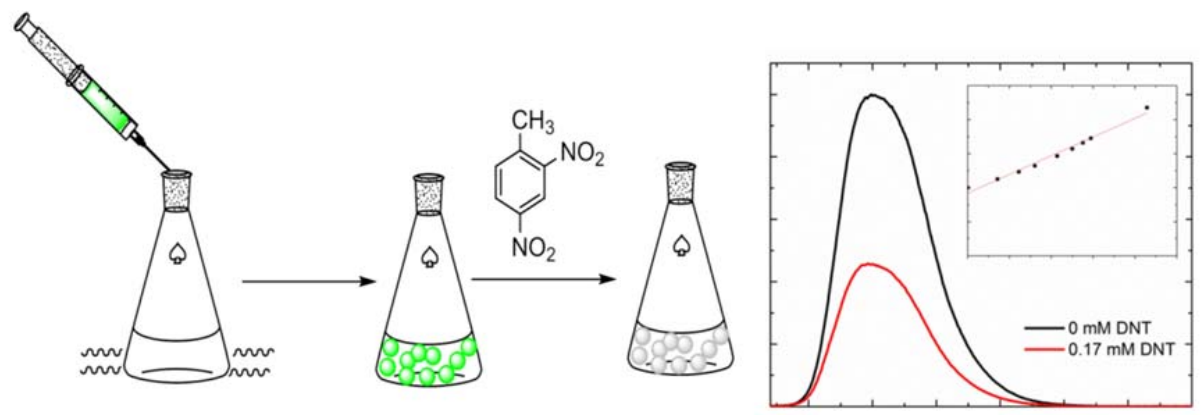


Chart 1: Electron-deficient analytes under investigation<smiles>Cc1c([N+](=O)[O-])cc([N+](=O)[O-])cc1[N+](=O)[O-]</smiles>

1 TNT<smiles>Cc1ccc([N+](=O)[O-])cc1[N+](=O)[O-]</smiles>

2 DNT

2,4,6-trinitrotoluene 2,4-dinitrotoluene nitrobenzene cyclohexanone<smiles>O=[N+]([O-])c1ccccc1</smiles>

3<smiles>O=C1CCCCC1</smiles>

4

Chart 2: Structures of the fluorescent organic polymers

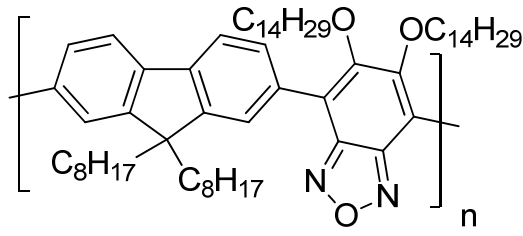

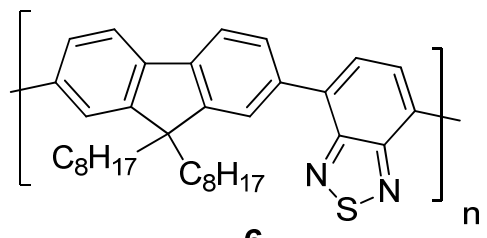

6

Scheme 1: Synthesis of PFBO 5:

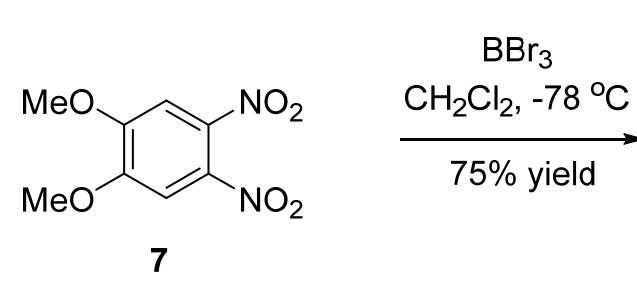

1. $\mathrm{NaN}_{3}, 20 \% \mathrm{TBABr}$ toluene, $110^{\circ} \mathrm{C}$

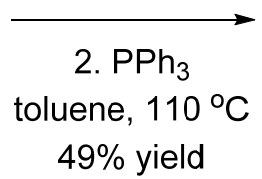
$49 \%$ yield

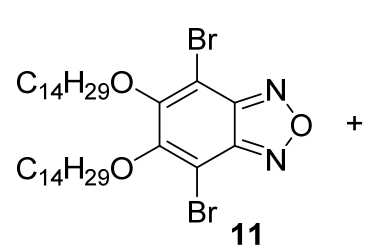

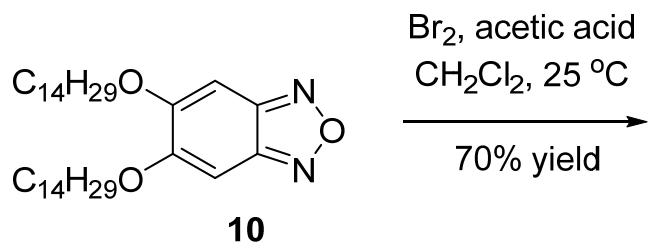

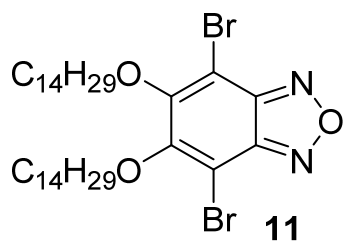

\section{$\mathrm{Pd}\left(\mathrm{PPh}_{3}\right)_{4}, \mathrm{Et}_{4} \mathrm{NOH}$}

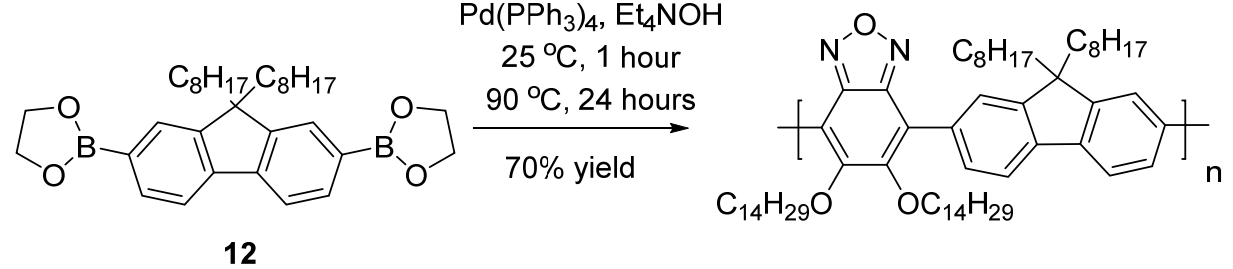

PFBO 5 
Scheme 2: Synthesis of PFBT 6:

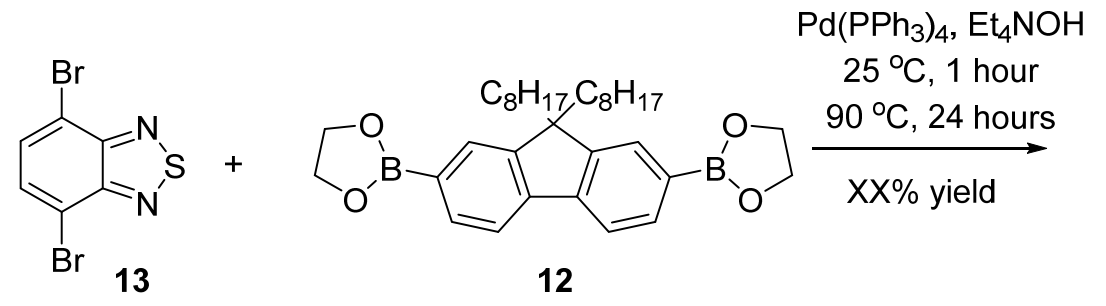

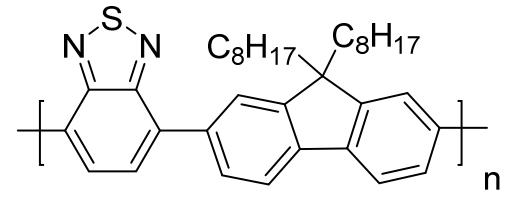

PFBT 6

Table 1: Properties of the PFBO and PFBT polymers

\begin{tabular}{|l|l|l|}
\hline & PFBO 5 & PFBT 6 \\
\hline$\lambda_{\max }$ abs & $413 \mathrm{~nm}$ & $452 \mathrm{~nm}$ \\
\hline$\lambda_{\max } \mathrm{em}$. & $507 \mathrm{~nm}$ & $532 \mathrm{~nm}$ \\
\hline $\mathrm{M}_{\mathrm{w}}$ & $8.8652 \times 10^{3} \mathrm{~g} / \mathrm{mol}$ & $1.7003 \times 10^{4} \mathrm{~g} / \mathrm{mol}$ \\
\hline PDI & 1.43 & 2.68 \\
\hline
\end{tabular}

Table 2: Properties of the PFBO and PFBT-derived nanoparticles

\begin{tabular}{|l|l|l|}
\hline & PFBO particles (5) & PFBT particles (6) \\
\hline$\lambda_{\max }$ abs & $411 \mathrm{~nm}$ & $458 \mathrm{~nm}$ \\
\hline$\lambda_{\max }$ em. & $534 \mathrm{~nm}$ & $536 \mathrm{~nm}$ \\
\hline Average size (DLS) & $24.4 \mathrm{~nm}$ & $18.2 \mathrm{~nm}$ \\
\hline
\end{tabular}

Table 3: Stern-Volmer constants obtained for each analyte-fluorophore combination (maximum analyte concentrations in parentheses)

\begin{tabular}{|l|l|l|}
\hline & DNT & TNT \\
\hline & & \\
\hline PFBT particles & $\begin{array}{l}4169 \mathrm{M}^{-1} \\
\left(0.17 \mathrm{mM}^{-1} \mathrm{DNT}\right)\end{array}$ & $\begin{array}{l}11974 \mathrm{M}^{-1} \\
\left(0.14 \mathrm{mM}^{-1} \mathrm{TNT}\right)\end{array}$ \\
\hline $\begin{array}{l}\text { PFBO } \\
\text { particles }\end{array}$ & $\begin{array}{l}6867 \mathrm{M}^{-1} \\
(0.17 \mathrm{mM} \text { DNT })\end{array}$ & $6737 \mathrm{M}^{-1}$ \\
\hline PFBT polymer & No quench & No quench \\
\hline $\begin{array}{l}\text { PFBO } \\
\text { polymer }\end{array}$ & No quench & No quench \\
\hline
\end{tabular}

$3.13 \%$ acetonitrile in water; $2.5 \times 10^{-4} \mathrm{mg} / \mathrm{mL}$ nanoparticles; $420 \mathrm{~nm}$ excitation wavelength for PFBT and $400 \mathrm{~nm}$ excitation wavelength for PFBO 


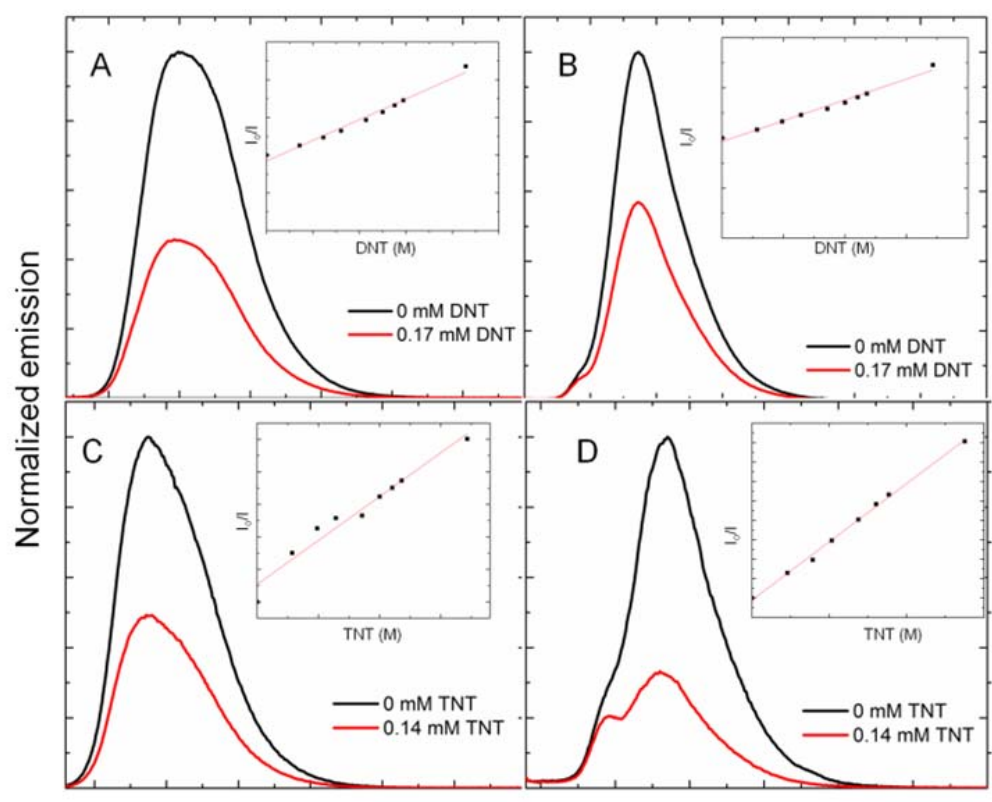

Wavelength $(\mathrm{nm})$

Figure 1: Examples of fluorescence quenching of (a) PFBT particles with DNT (b) PFBO particles with DNT (c) PFBT particles with TNT and (d) PFBO particles with TNT. SternVolmer plots are included as insets for each example.

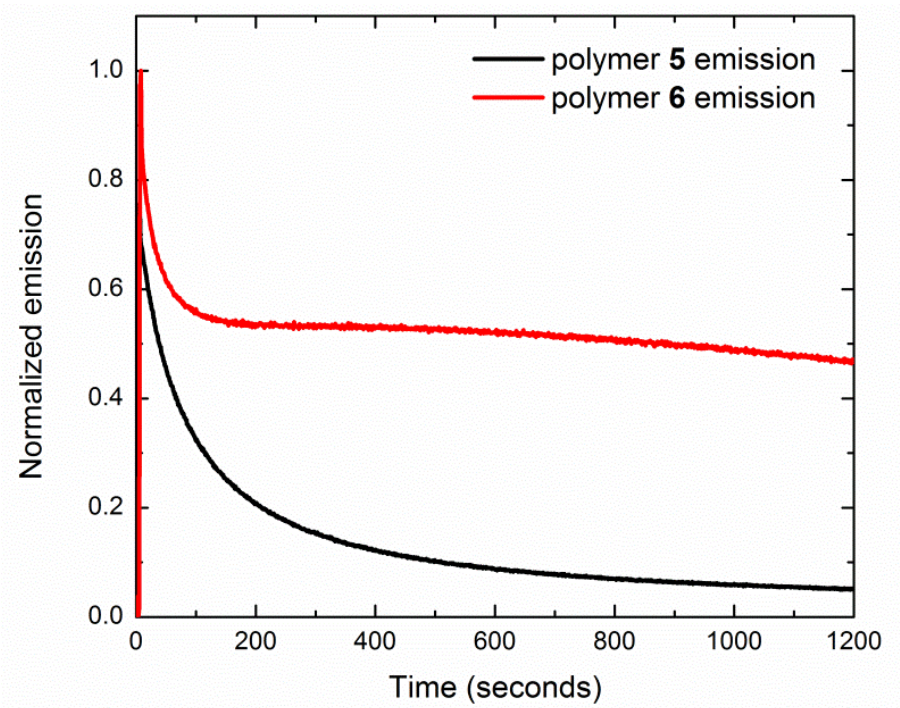

Figure 2: Quenching of fluorescent thin films in the presence of DNT vapor. Polymer 5 emission monitored at $500 \mathrm{~nm}$; polymer 6 emission at $533 \mathrm{~nm}$. 


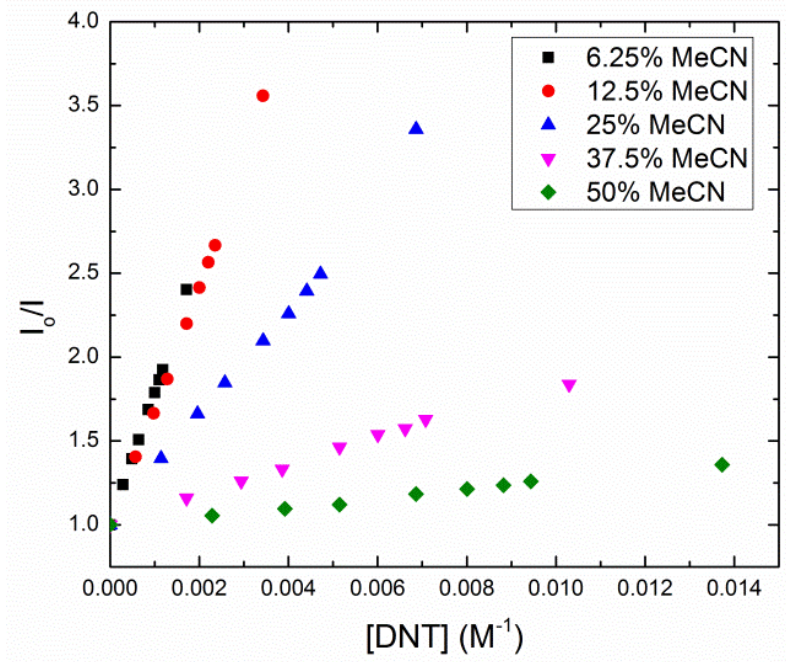

Figure 3: Dependence of $\mathrm{K}_{\mathrm{sv}}$ values on the acetonitrile/water ratio. Measurements were obtained for PFBT nanoparticles $\left(2.5 \times 10^{-4} \mathrm{mg} / \mathrm{mL}\right)$ in the presence of DNT.

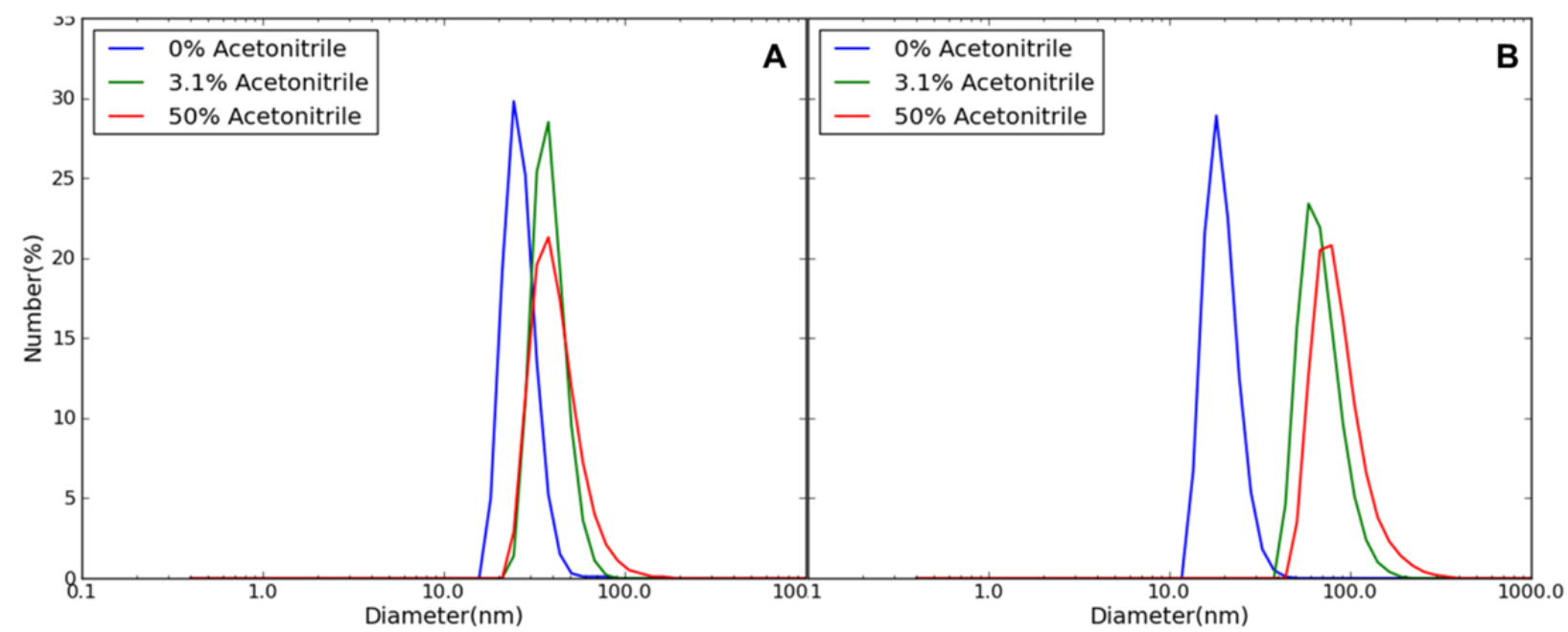

Figure 4: DLS measurements of (a) polymer 5 nanoparticles and (b) polymer 6 nanoparticles in the presence of increasing amounts of acetonitrile. 


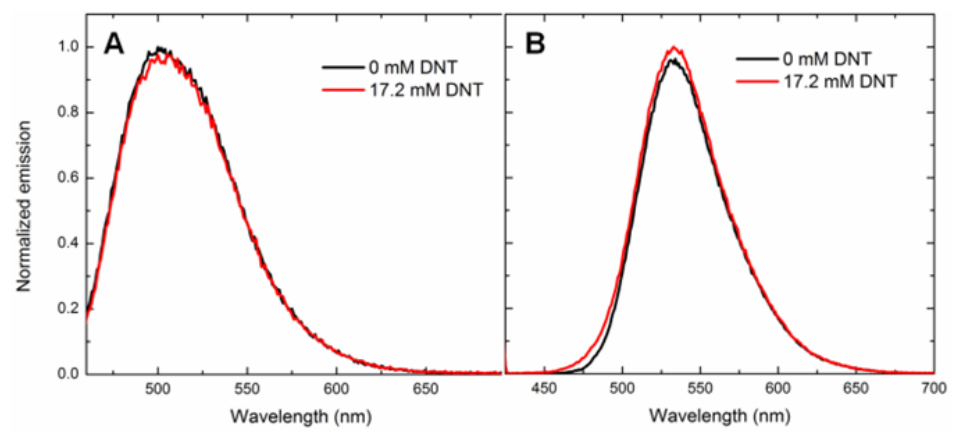

Figure 5: Insensitivity of (a) PFBO and (b) PFBT polymers to $17.2 \mathrm{mM}$ concentrations of DNT. 
Highly Efficient Quenching of Nanoparticles for the Detection of Electron-Deficient Nitroaromatics Patrick Marks, Sage Cohen, and Mindy Levine

Electronic Supplementary Information 


\section{TABLE OF CONTENTS}

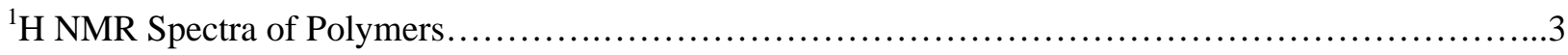

GPC Traces........................................................................

Summary Tables of Quenching Data..................................................... 5

Sample Graphs of Fluorescence Quenching................................................... 
${ }^{1} \mathrm{H}$ NMR SPECTRA:
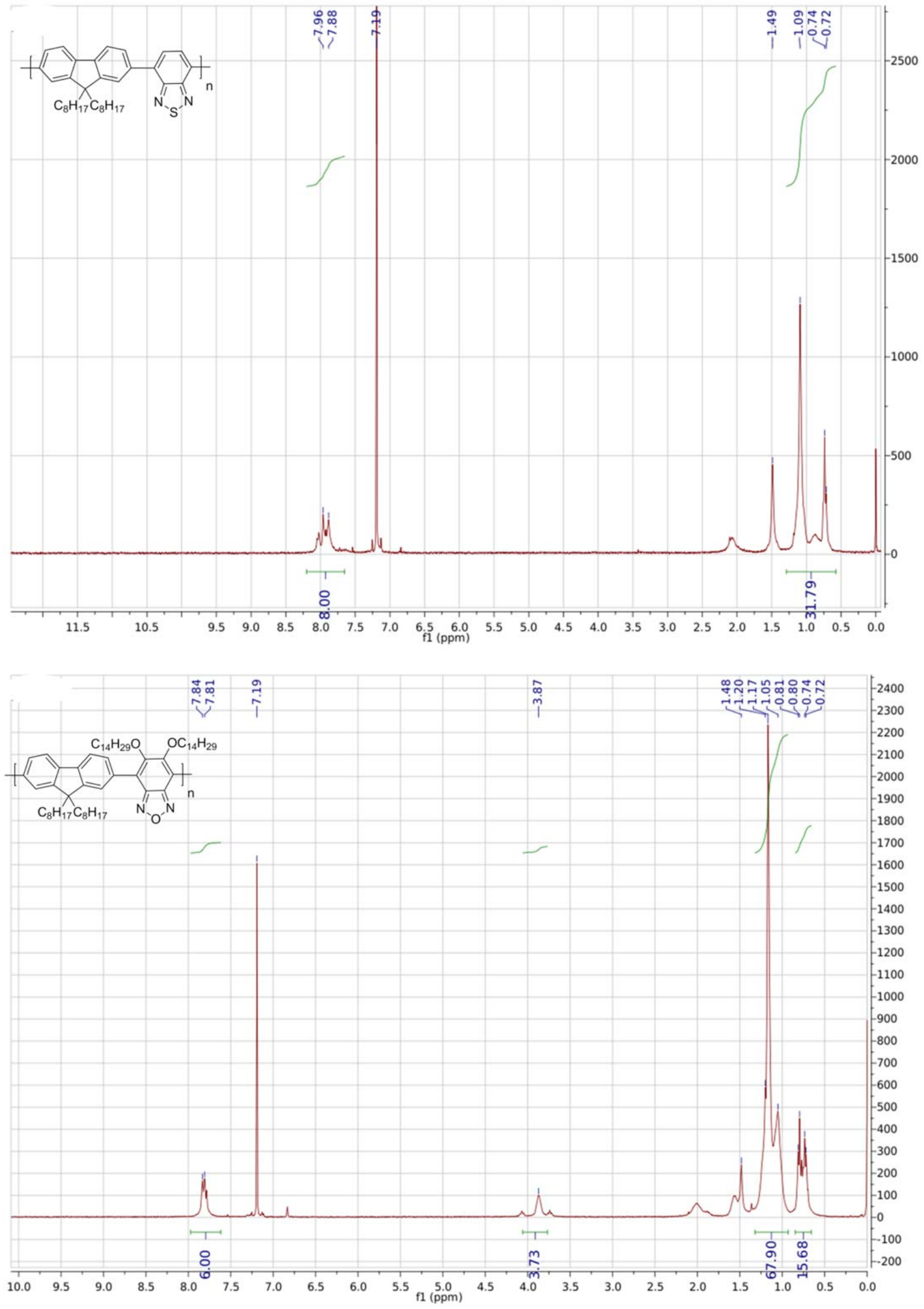


\section{GEL PERMEATION CHROMATOGRAPHY:}

The molecular weight and size distribution were determined by gel permeation chromatography.

\section{PFBO:}

$\mathrm{M}_{\mathrm{n}}=6.1976 \times 10^{3} \mathrm{~g} / \mathrm{mol}$

$\mathrm{M}_{\mathrm{w}}=8.8652 \times 10^{3} \mathrm{~g} / \mathrm{mol}$

$\mathrm{PDI}=1.43$

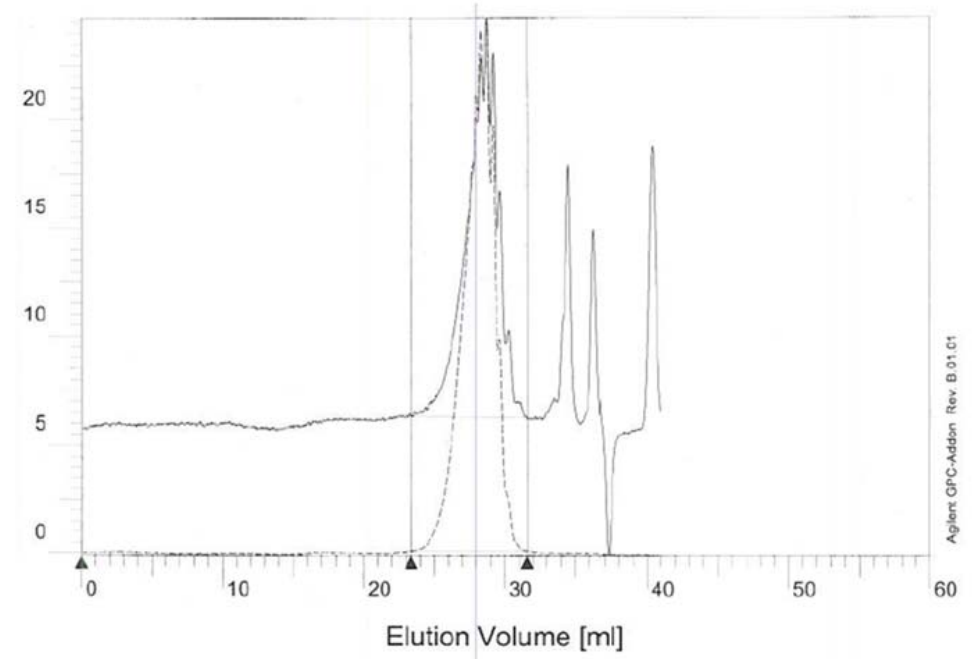

PFBT:

$\mathrm{M}_{\mathrm{n}}=6.3503 \times 10^{3} \mathrm{~g} / \mathrm{mol}$

$\mathrm{M}_{\mathrm{W}}=1.7003 \times 10^{4} \mathrm{~g} / \mathrm{mol}$

PDI $=2.68$

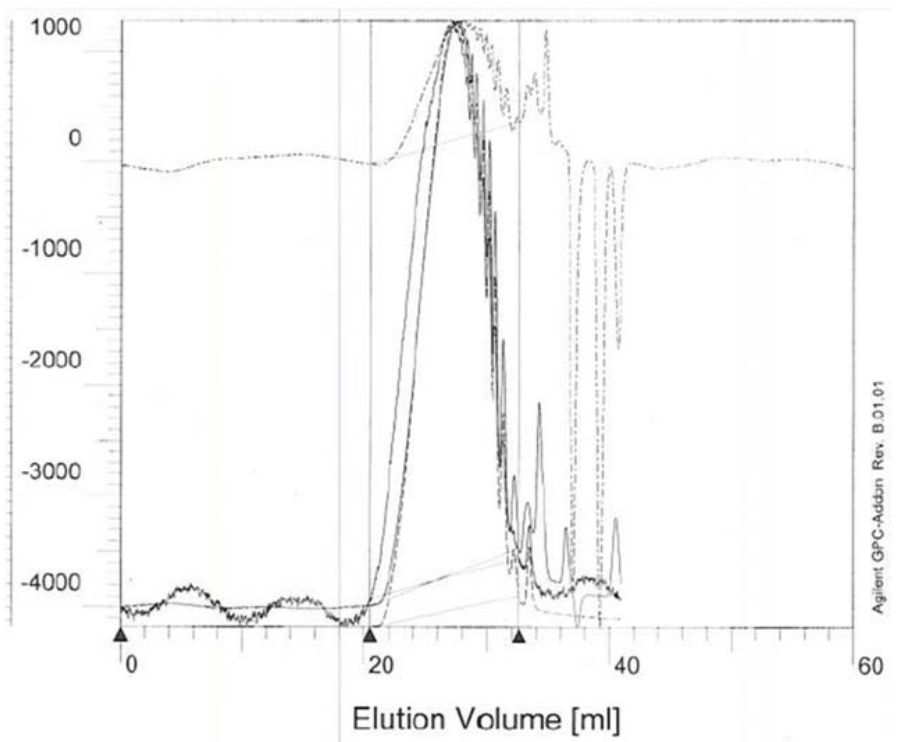




\section{SUMMARY TABLES OF QUENCHING DATA}

\section{Quenching of PFBO particles with DNT:}

Three different conditions were tried, and representative data are shown below:

\begin{tabular}{|c|l|l|}
\hline conditions & $\mathrm{K}_{\mathrm{sv}}$ & \% quenching \\
\hline $\mathbf{A}$ & $1723 \mathrm{M}^{-1}$ & $73 \%$ quenched at $1.72 \mathrm{mM}$ DNT \\
\hline B & $6867 \mathrm{M}^{-1}$ & $54 \%$ quenched at $0.172 \mathrm{mM}$ DNT \\
\hline $\mathbf{C}$ & $287 \mathrm{M}^{-1}$ & $67 \%$ quenched at $6.86 \mathrm{mM}$ DNT \\
\hline
\end{tabular}

Condition A: $6.25 \%$ acetonitrile in water, $2.5 \times 10^{-4} \mathrm{mg} / \mathrm{mL}$ particle concentration

Condition B: $3.13 \%$ acetonitrile in water, $2.5 \times 10^{-4} \mathrm{mg} / \mathrm{mL}$ particle concentration

Condition C: $25 \%$ acetonitrile in water, $1.25 \times 10^{-3} \mathrm{mg} / \mathrm{mL}$ particle concentration

\section{Quenching of PFBT particles with DNT:}

Three different conditions were tried, and representative data are shown below:

\begin{tabular}{|c|l|l|}
\hline conditions & $\mathrm{K}_{\mathrm{sv}}$ & \% quenching \\
\hline B & $4169 \mathrm{M}^{-1}$ & $42 \%$ quenched at $0.172 \mathrm{mM}$ DNT \\
\hline $\mathbf{D}$ & $431 \mathrm{M}^{-1}$ & $75 \%$ quenched at $6.86 \mathrm{mM}$ DNT \\
\hline $\mathbf{E}$ & $485 \mathrm{M}^{-1}$ & $78 \%$ quenched at $6.86 \mathrm{mM}$ DNT \\
\hline
\end{tabular}

Condition B: $3.13 \%$ acetonitrile in water, $2.5 \times 10^{-4} \mathrm{mg} / \mathrm{mL}$ particle concentration

Condition D: $25 \%$ acetonitrile, $2.5 \times 10^{-4} \mathrm{mg} / \mathrm{mL}$ particle concentration

Condition E: $25 \%$ acetonitrile, $2.5 \times 10^{-3} \mathrm{mg} / \mathrm{mL}$ particle concentration

We also directly investigated the effect of acetonitrile on the quenching constants. The concentration of nanoparticles was kept constant at $2.5 \times 10^{-4} \mathrm{mg} / \mathrm{mL}$, and the amount of acetonitrile was varied from $6.25 \%$ to $50 \%$. Representative data are shown below:

\begin{tabular}{|c|l|l|}
\hline Percent $\mathrm{CH}_{3} \mathrm{CN}$ & $\mathrm{K}_{\mathrm{sv}}$ & \% quenching \\
\hline 6.25 & $804 \mathrm{M}^{-1}$ & $58 \%$ at $1.72 \mathrm{mM}$ DNT \\
\hline 12.5 & $739 \mathrm{M}^{-1}$ & $72 \%$ at $3.43 \mathrm{mM}$ DNT \\
\hline 25 & $332 \mathrm{M}^{-1}$ & $70 \%$ at $6.86 \mathrm{mM}$ DNT \\
\hline 37.5 & $83 \mathrm{M}^{-1}$ & $46 \%$ at $10.3 \mathrm{mM} \mathrm{DNT}$ \\
\hline 50 & $27 \mathrm{M}^{-1}$ & $26 \%$ at $13.7 \mathrm{mM}$ DNT \\
\hline
\end{tabular}

\section{PFBT polymer with DNT:}

Observed a slight increase in the fluorescence emission in the presence of increasing amounts of DNT. At $1.72 \mathrm{mM}$ of DNT, $102 \%$ of the original particle fluorescence was observed.

\section{PFBO polymer with DNT:}

No quenching observed.

PFBO particles with TNT: 
This quenching was investigated using conditions B: 3.13\% acetonitrile in water, with a nanoparticle concentration of $2.5 \times 10^{-4} \mathrm{mg} / \mathrm{mL}$. Under these conditions, $\mathrm{K}_{\mathrm{sv}}=6737 \mathrm{M}^{-1}$, with $50 \%$ quenching at 0.14 mM TNT.

\section{PFBT particles with TNT:}

This quenching was investigated using conditions B: $3.13 \%$ acetonitrile in water, with a nanoparticle concentration of $2.5 \times 10^{-4} \mathrm{mg} / \mathrm{mL}$. Under these conditions, $\mathrm{K}_{\mathrm{sv}}=11974 \mathrm{M}^{-1}$, with $62 \%$ quenching at 0.14 mM TNT.

\section{PFBO and PFBT polymers with TNT:}

This quenching was investigated using 3.13\% acetonitrile in THF, with a nanoparticle concentration of $2.5 \times 10^{-4} \mathrm{mg} / \mathrm{mL}$. No quenching was observed for either the PFBO or the PFBT polymers. 


\section{SAMPLE GRAPHS OF FLUORESCENCE QUENCHING}

\section{PFBO particles with DNT:}

\section{Conditions A:}
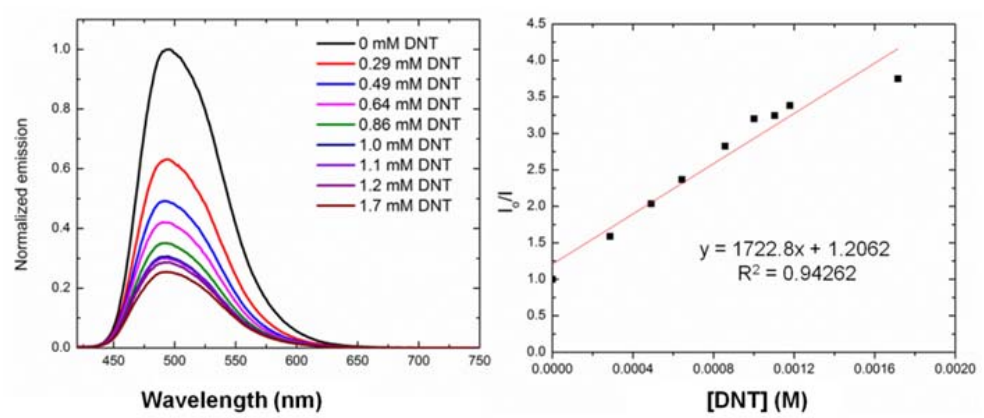

Conditions B:
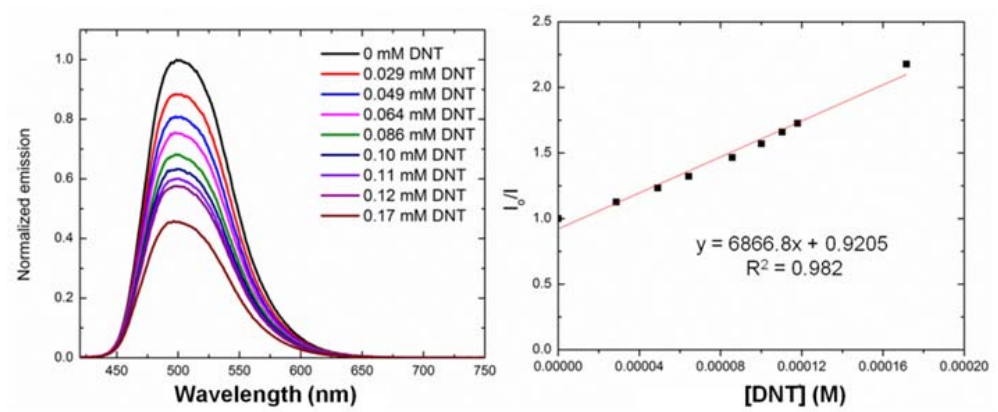

Conditions C:
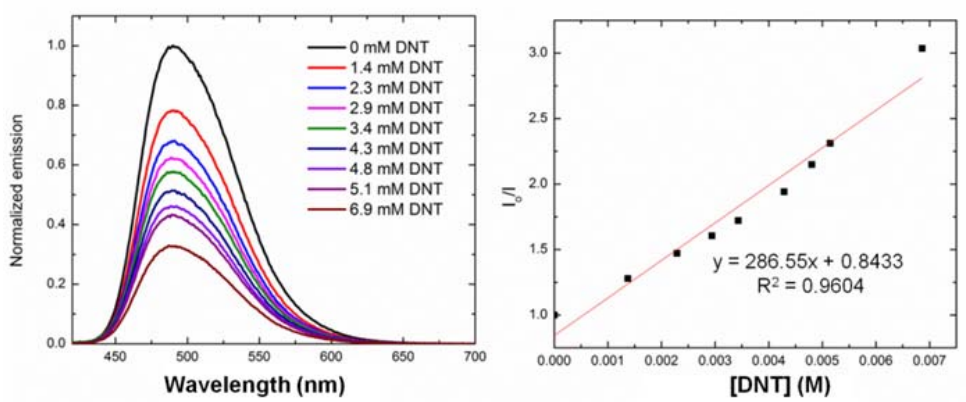


\section{PFBT particles with DNT:}

\section{Conditions B:}
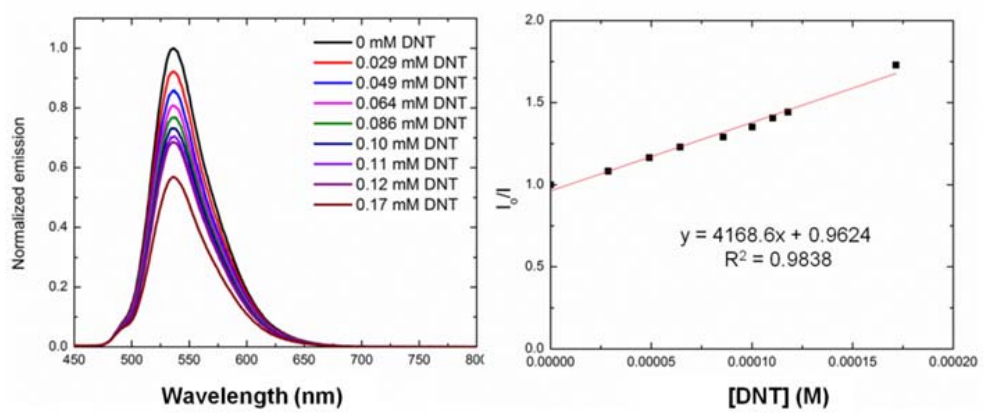

\section{Conditions D:}
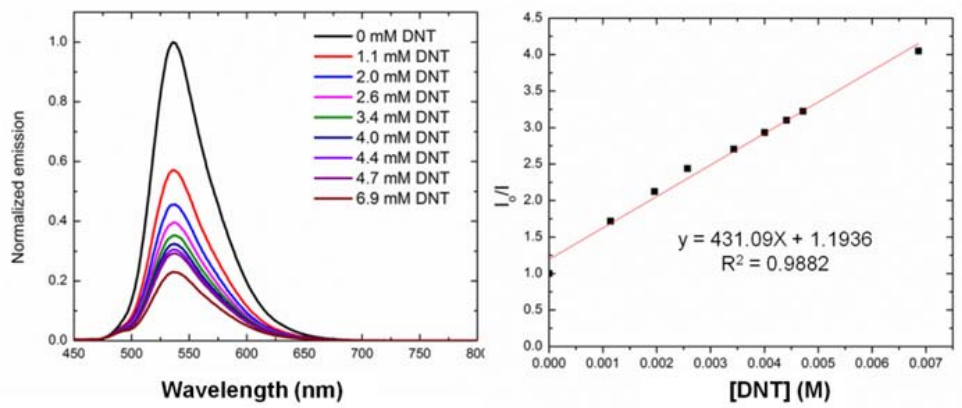

Conditions E:
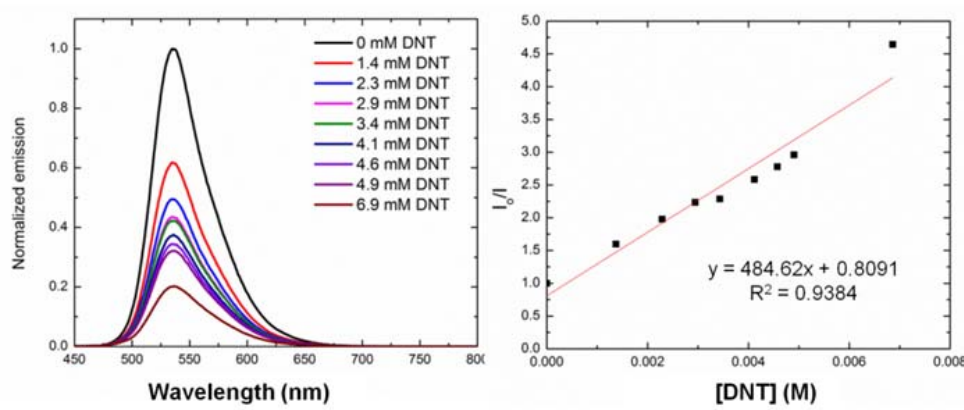

Direct comparison of how the ratio of acetonitrile/water affects the quenching efficiencies:

$6.25 \%$ acetonitrile:

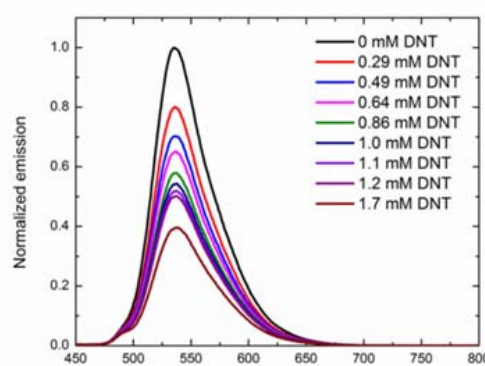

Wavelength $(\mathrm{nm})$

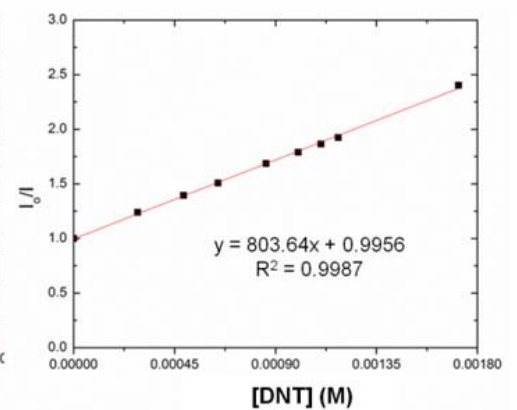

12.5\% acetonitrile: 

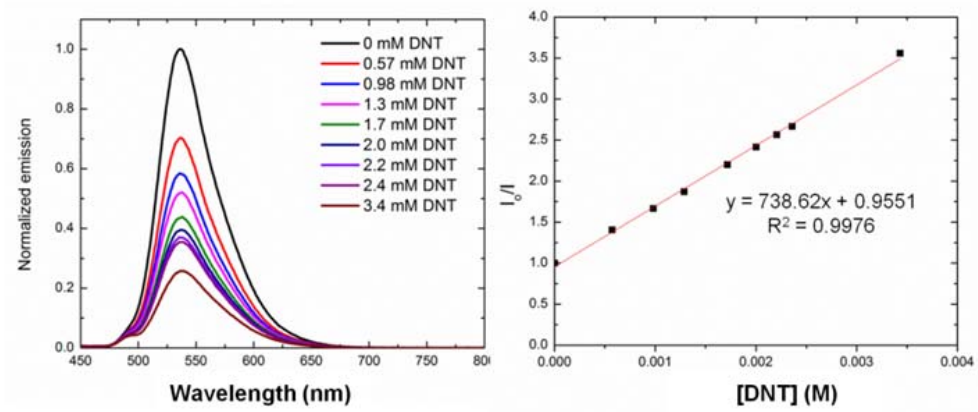

25\% acetonitrile:

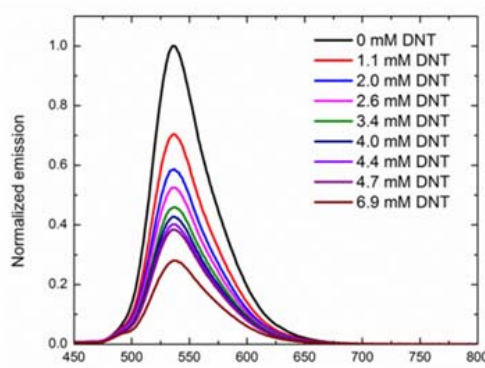

Wavelength (nm)

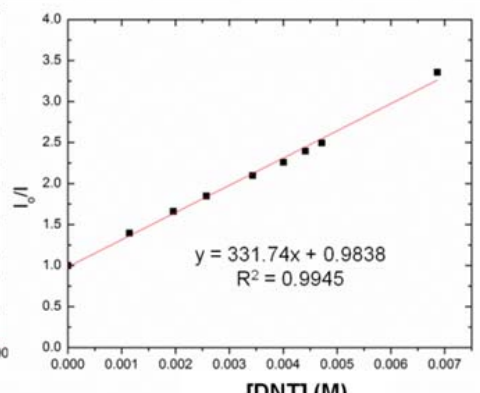

37.5\% acetonitrile:
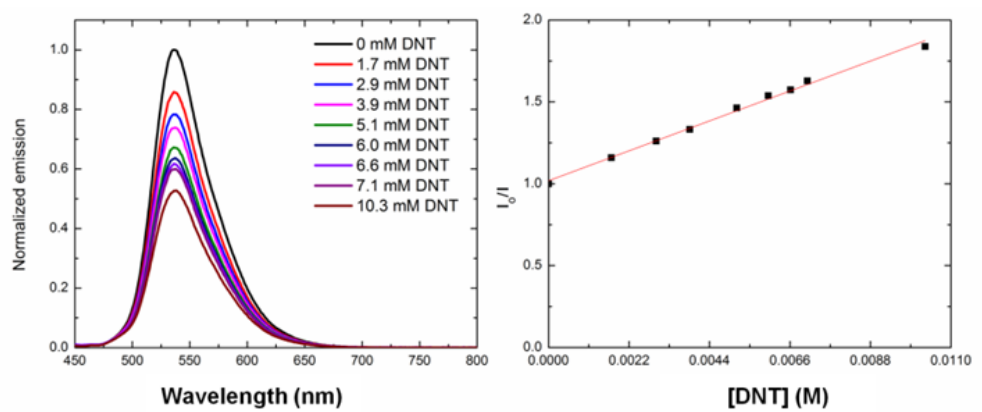

50\% acetonitrile:
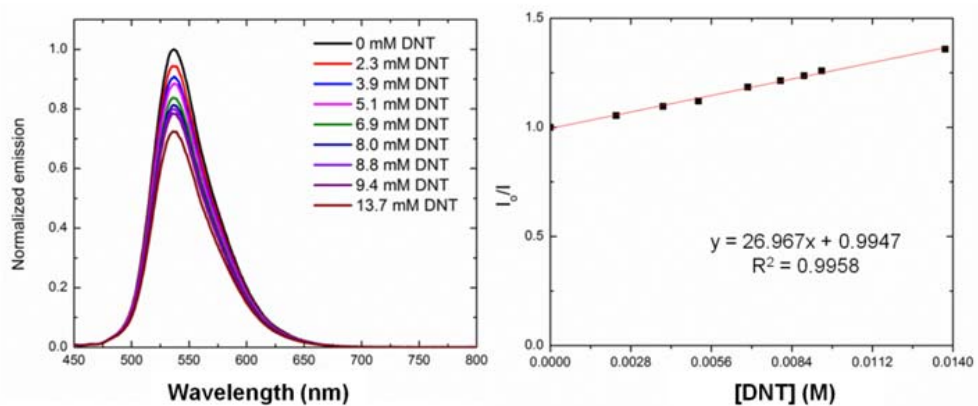


\section{PFBT POLYMER WITH DNT}
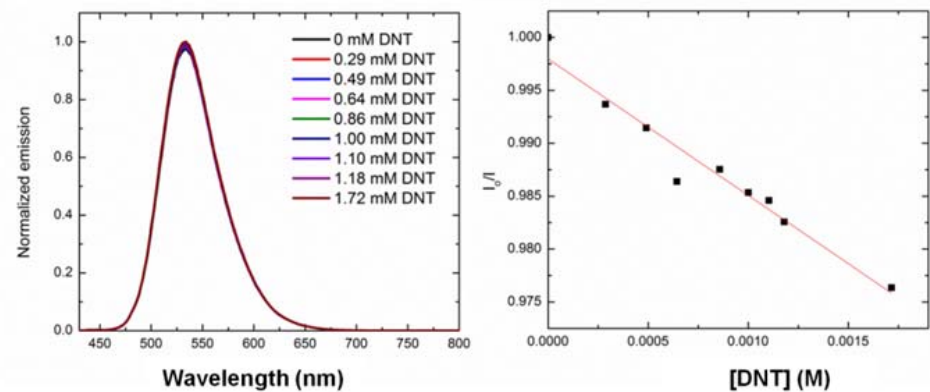

\section{PFBO POLYMER WITH DNT:}
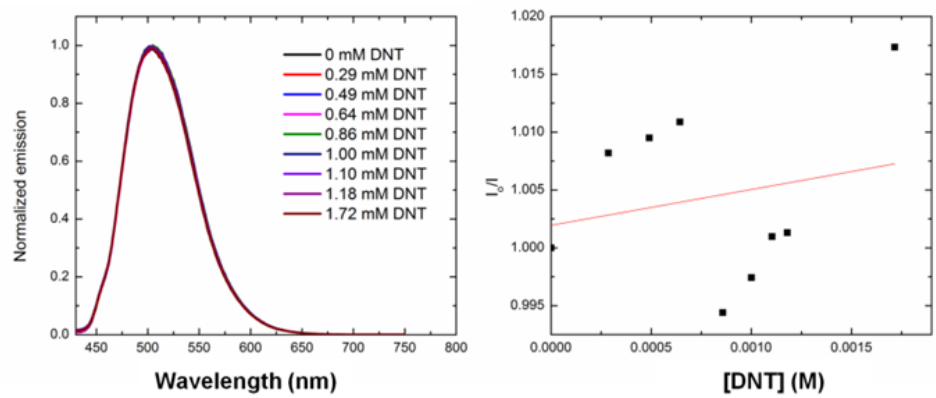

PFBT PARTICLES WITH TNT:
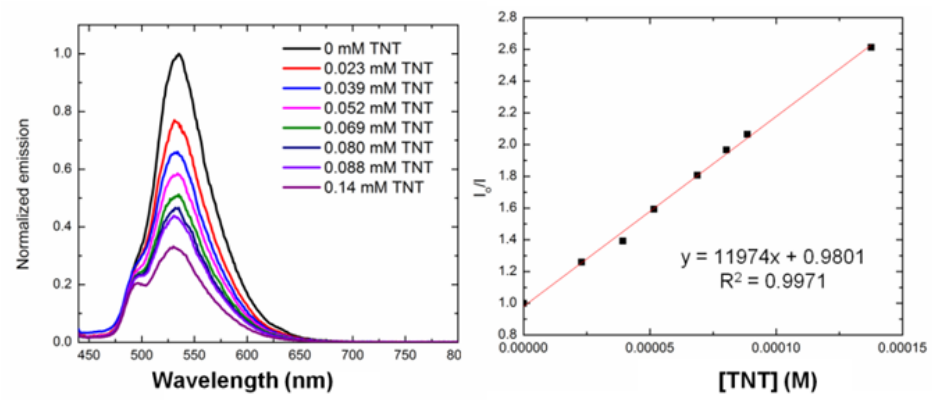

PFBO PARTICLES WITH TNT:
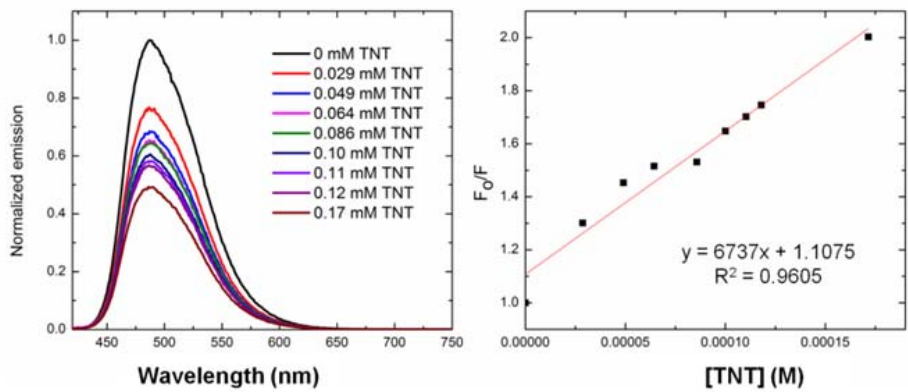

PFBT POLYMER WITH TNT: 

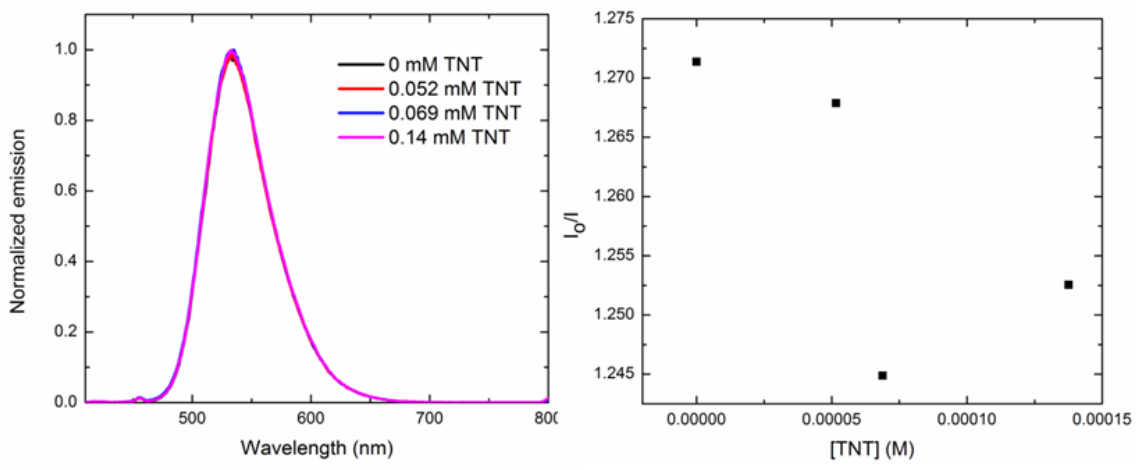

PFBO POLYMER WITH TNT:
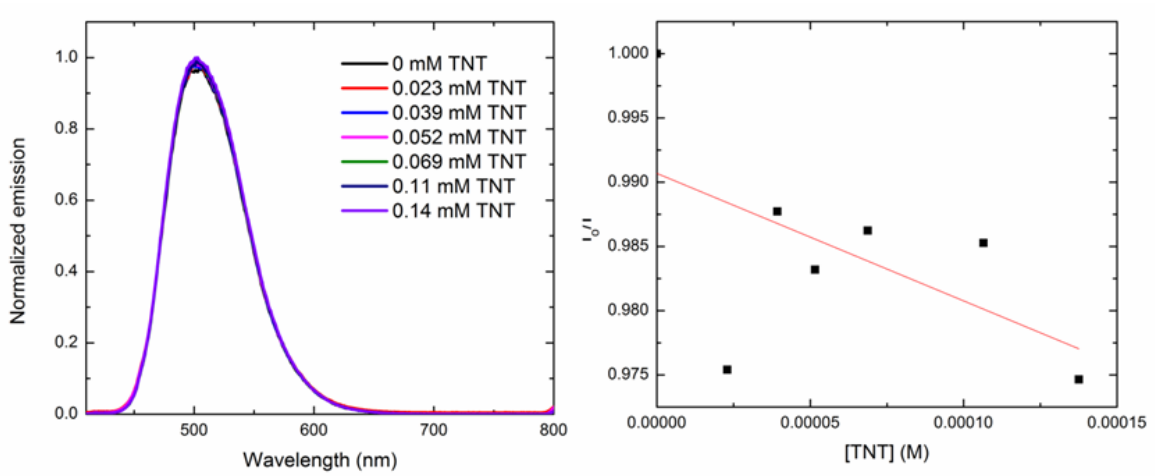